\title{
Correction to: Esophagogastric junction adenocarcinomas: individualization of resection with special considerations for Siewert type II, and Nishi types EG, E = G and GE cancers
}

\author{
Arnulf H. Hölscher ${ }^{1,2}\left[\right.$ [D $\cdot$ Simon Law ${ }^{3}$
}

Published online: 12 December 2019

(c) The International Gastric Cancer Association and The Japanese Gastric Cancer Association 2019

\section{Correction to: Gastric Cancer \\ https://doi.org/10.1007/s10120-019-01022-x}

The authors would like to correct the error in the publication of the original article. The correction detail is given below:

The last sentence under the heading "Introduction" should read as "The Japanese Esophageal Society subclassification of Nishi's proposal has 5 types, depending on the relative extent of esophageal or gastric involvement $(\mathrm{E}, \mathrm{EG}, \mathrm{E}=\mathrm{G}$, GE and $\mathrm{G}$ ) and true cardia cancer is mostly represented by the EG, E=G or GE type Nishi tumors [4]."

The original article can be found online at https://doi.org/10.1007/ s10120-019-01022-x.

Arnulf H. Hölscher

arnulf.hoelscher@fdk.info

1 Center for Esophageal and Gastric Cancer Surgery, AGAPLESION Markushospital Frankfurt,

Wilhelm-Epstein-Strasse 4, 60431 Frankfurt am Main, Germany

2 Contilia Center for Esophageal Diseases, Elisabeth Hospital Essen, Essen, Germany

3 Department of Surgery, Queen Mary Hospital, The University of Hong Kong, Hong Kong (SAR), China
Publisher's Note Springer Nature remains neutral with regard to jurisdictional claims in published maps and institutional affiliations. 